\title{
Basic Income, Wages, and Productivity: A Laboratory Experiment
}

\author{
${ }^{1}$ Faculty of Social Sciences, Tampere University, Kalevantie 5, Tampere, Finland, E-mail: veera.jokipalo@tuni.fi
}

\begin{abstract}
:
This paper reports the results of an economic lab experiment designed to test the impact of Basic Income (BI) on wages and productivity. The experimental design is based on the classic gift exchange game. Participants assigned the role of employer were tasked with making wage offers, and those assigned as employees chose how hard they would work in return. In addition to a control without any social security net, BI was compared to unemployment benefits, and both types of cash transfers were tested at two levels. The results are that wage offers were increased in both the BI and unemployment benefit treatments compared to the control. The higherlevel BI treatment also significantly increased effort. Further experimentation could shed more light on how the potential extra value created in the labor market through increased productivity would be divided between employers and employees.
\end{abstract}

Keywords: Basic Income, laboratory experiments, gift exchange, labor market equilibrium, productivity

DOI: $10.1515 /$ bis-2019-0016

Numerous trials and studies on Basic Income (BI) or policies resembling it have been conducted in the last 50 years, and new field experiments have been cropping up in recent years especially. Even so, there does not seem to be any overarching consensus about the effects of a BI policy on the labor market. The existing empirically collected information is better fit to answer more narrow questions (Widerquist, 2018), and in general it is difficult to draw unambiguous conclusions from past research projects. Perhaps the biggest hurdle is the unobservability of long-term and dynamic effects in experimental designs with fixed durations and geographically dispersed test subjects (Calnitsky, 2019). This is not to say that field experiments do not have their own considerable advantages. Rather than dismiss the valuable research already conducted, I aim to complement it with economic laboratory experiments.

Economic lab experiments usually entail tasking human participants with playing a game in a monitored computer lab. A financial incentive is created by rewarding participants with cash according to their success. When other relevant factors mimic reality well enough, hypotheses about behavior in the real world can be made based on the results. As pointed out by Noguera and De Wispelaere (2006) who argue that lab experiments should be conducted to investigate BI, laboratory experiments are also less susceptible to politically motivated manipulation and noise from uncontrolled variables than field studies. Furthermore, the authors suggest that experiments could be used to investigate specific behavioral and psychological aspects of how a BI would possibly affect decision-making in society.

Another specific advantage of lab experiments over field experiments in BI research is that it is possible to keep the variable of interest, a simulated BI scheme, constant over an experimental session and uniform for all participants. The main drawback in this methodology is the fact that participants are not observed in their natural environments, and some factors present in real life will always be missing from the design. This is, of course, the most important advantage of field experiments. Due to their opposing strengths and weaknesses, I suggest that combining knowledge from field experiments and laboratory experiments is currently the best we can do to estimate the impact of BI without full-scale implementation of the policy.

Yet, to my knowledge, there has been only one published experiment on the labor market impact of BI. In this experiment, Haigner, Höchtl, Jenewein, Schneider, and Wakolbinger (2012) studied the effect of a BI scheme on labor supply. Participants could earn money by completing small computerized tasks. The researchers found that a BI treatment, in which participants received a uniform lump sum of 15 euros and 'wages' were heavily taxed, did not significantly affect the number of tasks completed compared to a scenario without a cash transfer policy. For the research reported here, I designed an experiment where not only labor supply, but also labor demand and wages were allowed to vary according participants' decisions. This way, dynamic effects between these factors could be observed. The final design is a modified version of the classic gift exchange experiment (Fehr, Kirchsteiger, \& Riedl, 1993). 


\section{$\mathrm{BI}$ and labor market behavior}

This section first presents a framework to approach the potential impact of BI on labor market behavior. Focus is given to the behavior of employees, especially labor supply decisions. First, to see why an economist's gut feeling is that BI would decrease labor supply, consider Figure 1. A worker's decision to enter the labor market will depend on how well they are compensated for the loss of leisure time, as both leisure and consumption possibilities are important to the individual. The budget line (dark blue) plots the combinations of consumption and leisure time attainable, as dictated by the hourly wage and other sources of income. Each indifference curve (green) plots combinations of consumption and leisure between which the worker is indifferent. If these indifference curves represent true preferences of workers, and all else is held constant, an increase in non-labor income - such as a BI transfer - results in a reduction in working hours. This is because the worker chooses the point where their budget line meets the highest possible indifference curve. As the budget line is shifted upward (indicated with grey arrows), the worker makes a move from $l_{1}^{*}$ to $l_{2}^{*}$, simultaneously increasing both consumption and leisure. It seems obvious that people would choose such an unequivocal improvement. Yet, there exist competing predictions of the impact of BI on the labor market, even among economists. This is ultimately not surprising, as the impact depicted in Figure 1 depends on a number of specific assumptions not universally agreed upon.

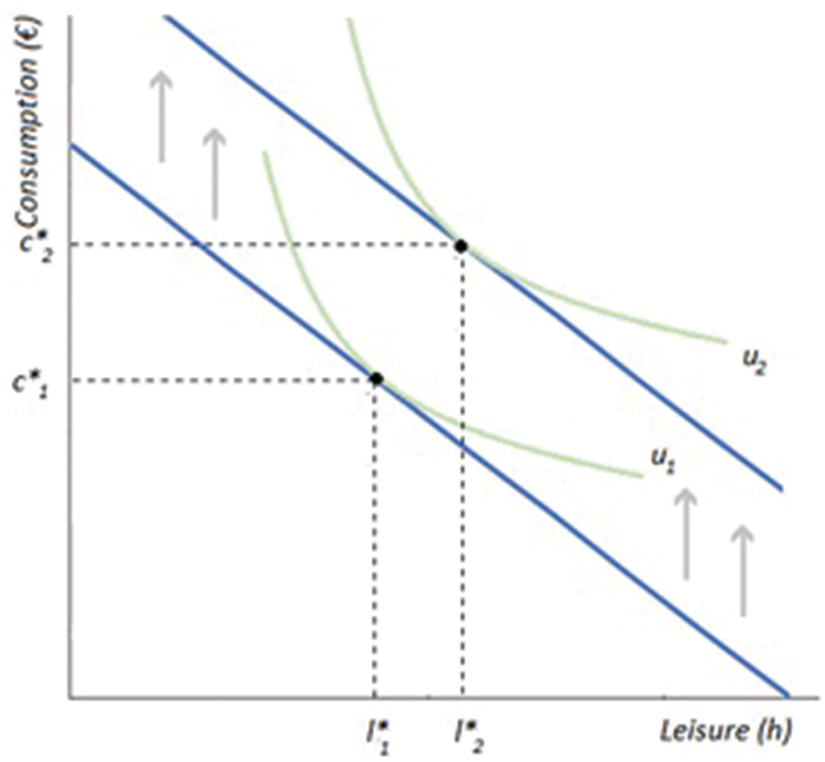

Figure 1: Impact of basic income on labor supply.

\section{Determining the shape of the indifference curves}

The indifference curves depicted in Figure 1 are shaped with the assumption that on average, people dislike paid work and want as much consumption (income) and leisure time as possible. This does not seem like a completely outrageous assumption. However, the exact shape of the indifference curves has a significant bearing on labor supply decisions, and it cannot be defined without a more detailed assessment: If people dislike labor on average, how strongly do they feel about it? At what point is a ten-euro increase in income or a ten-minute increase in leisure vital, and when does it become negligible? It is also noteworthy that average preferences do not relay the whole picture: different groups can have different preferences and, as a result, different reactions to a BI policy.

The idea of people enjoying work goes against an economist's intuition to define paid labor as something that is not desirable - after all, why else would people demand wages in exchange for their effort? This can be countered with empirical evidence. For example, studies on win-for-life lottery winners show that even an indefinite source of adequate non-labor income does not suppress all willingness to work (Marx \& Peeters, 2008). Such a decision can be made because of improved social status, social relations in the workplace, or finding one's job meaningful, to give a few examples.

Work in and of itself is of course not necessarily beneficial or enjoyable for everyone, and some jobs can be downright detrimental to wellbeing. Instead, some may prefer to work because labor supply decisions are not made in a vacuum, but in anticipation of the future. A person's wage-earning ability may be low today, say, for 
lack of experience, but participation in the labor market today may bring considerable benefits tomorrow - and vice versa, choosing to exit the labor force can be detrimental if a person wished to re-enter later on (see e. g. Birnbaum \& Wispelaere, 2016). The hope of a better future might make a person less willing to give up working hours today. Relying on a BI transfer and forgoing such future benefits may still be a tempting option for those who strongly discount future welfare.

Finally, time spent outside of paid work is not quite as 'leisurely' for everyone, as many spend this extra time in unpaid work instead. They may be more likely to reduce working hours to either increase time spent on unpaid work, or increase leisure, as their actual leisure is much scarcer and thus more valuable to them. ${ }^{1}$ Others may generally require more downtime due to issues such as high stress levels or long-term illness, or need more income simply to cover their basic needs due to circumstances like high costs of health care.

Preferences can, to some extent, be deduced by observing behavior under different circumstances. Separating between similar effects of disliking labor and enjoying leisure is certainly a challenge to research design, but not technically impossible. However, if BI were to change preferences, for example through weakening social norms regarding work, the issue becomes ever more complicated.

\section{Determining the shape of the budget line}

The second part of the equation, the budget line, is perhaps simpler to determine, but also affected by several factors that must be considered simultaneously. Importantly, we must consider how the shape and positioning of the line would change as a BI policy is implemented in a given economy. Firstly, this is affected by other preand post-BI social policy measures. This includes policies such as unemployment benefits, social assistance and tax credits which are unlikely to remain completely unchanged if BI is implemented. The shape of the budget line would be impacted especially at the point where working hours are at zero or very little above that. Secondly, the tax system should be considered. Taxation of both labor and non-labor income can have a considerable impact on disposable income, which is what the individual considers when making their decision. Thirdly, specifics of the BI policy, especially the size of the transfer, can change the level of the budget line significantly.

Fourthly, if wages were to change as BI is implemented, potential income from labor would change (all else held equal). In a free economy, wages are theoretically determined by demand and supply of labor only. Reality is somewhat complex in that all three factors can be changed independently and affect each other dynamically. This accentuates the need for research on long-term and dynamic effects of BI. For example, if BI were to boost demand for goods and services in the economy through increasing the purchasing power of the poor (in a Keynesian vein), this could result in an increase in labor demand and thus wages and, in turn, labor supply. The possibility of BI having a direct impact on wages is central to my research and is explored further in the rest of this section.

\section{BI, labor supply, and wages: Theory and empirical evidence}

A meta-study on the labor supply response in BI field experiments has recently been published by Gilbert, Murphy, Stepka, Barrett, and Worku (2018). Pooling together all applicable datasets, the impact on labor supply was not statistically significant. The preliminary results from Finland, published too late to be included in the analysis of Gilbert et al., have come up with a similar result; no statistically significant difference in labor supply (Kangas, Jauhiainen, Simanainen, \& Ylikännö, 2019). Notably, not all these experiments are directly comparable due to difference in design and the societies in which they were conducted, and they carry the usual drawbacks of field experiments, nearly always lacking the ability to study long-term and dynamic effects. Studies on winfor-life lottery winners (Marx \& Peeters, 2008) are certainly long-term, but do not offer a view into dynamic effects. The Mincome experiment in Dauphin offered a BI transfer to all residents of a small town but was not long-term.

There is evidence of wages increasing in the Mincome experiments (Calnitsky \& Latner, 2017). The fact that the Mincome experiment entailed cash transfers available to all eligible residents lends some support to generalizing this result despite other experiments not reporting such effects. For example, in the Finnish experiment, those receiving BI transfers were not found to have different wages from the control group (Kangas et al., 2019). This suggests that if wages were to be increased, it would likely be due to dynamic effects. Why this would be remains a question unanswered through empirical investigation but explored to some extent theoretically.

Perhaps the most popular hypothesis is that BI would improve the bargaining power or workers, either as individuals or as collective actors in trade unions. If BI could bolster collective action by serving as an inexhaustible strike fund, unions might be able to negotiate for higher wages and better conditions overall. As 
pointed out in Calnitsky (2018), this may not be the case if people are currently involved in collective action only because they have no other option. But even if the improved position in negotiations only applied to individuals, there could be an increase in average wages. The potential increase in negotiation power is usually attributed to the 'exit option' or the 'power to say no', meaning that people would be able to decline atrocious labor contracts and rely on BI transfers instead as they wait for a better offer (Widerquist, 2013). If the effect is individual, inequalities may result; Birnbaum and Wispelaere (2016) posit that those in most vulnerable positions in the labor market would not enjoy such an improved bargaining position, but rather have the option to either stick with their current jobs or make way for those willing to take them. In contradiction, Pech (2010) has suggested that wages would decrease for coveted jobs and increase for those with less appeal. This would result from the fact that with $\mathrm{BI}$, people are less dependent on wages to make ends meet and can afford to choose professions they enjoy; and some jobs are more universally appealing than others.

Increased labor supply, measured through the employment rate of average number of hours worked, is not the only way BI may influence the total amount of work performed. Another possible channel is through productivity. An increase in productivity could theoretically take place through improved welfare. The positive impact of BI on health, especially mental health, is perhaps the most widely observed result from field experiments to date (see e. g. Beck, Pulkki-Brännström, \& San Sebastián, 2015; Forget, 2011; Kangas et al., 2019). This improvement in welfare could translate into not only higher productivity at work, but also increased labor supply. As noted by Van der Veen (2019), BI may increase labor supply indirectly by reducing cognitive load on the poor, as they no longer need to spend as much mental energy simply to make ends meet (such effects of poverty have been studied in Mani, Mullainathan, Shafir, \& Zhao, 2013). The final part of this section considers a gift exchange behavior as another specific channel through which BI could impact productivity.

\section{Gift exchange behavior}

George Akerlof (1982) famously asserts that some labor contracts implicitly include partial gift exchange. This means that employers sometimes offer higher wages than would be necessary to fill vacancies because they believe employees will reciprocate with higher effort than necessary to keep their jobs. The goal is thus higher production per dollar paid in wages. Employees might also increase effort in hopes that this will be rewarded by better wages. In other words, gift exchange behavior can be summarized as a reciprocal relationship where employers pay wages above market-clearing and employees exert effort over the minimum requirement. If we accept the notion that gift exchange occurs in the labor market, the theory offers both a baseline for explaining behavior that does not follow basic economic theory, and one channel through which BI could impact behavior in the labor market in general. Notably, similar effects could sometimes be elicited by conditional transfers such as unemployment benefits, which are already place in many societies; it is important to compare BI not only to lack of social security, but also to the status quo.

In the gift exchange model, employees consider the wages paid elsewhere as well as benefits paid to the unemployed to compare their own wages against. According to this, they decide whether they are being paid fairly. According to the fair wage-effort hypothesis (Akerlof, 1982; Akerlof \& Yellen, 1990), an employee's perception of a fair wage influences their effort level: a person paid less than what they think is fair will decrease their effort proportionately. Employers can thus potentially make gains from offering wages higher than market-clearing, up to a 'fair wage', as effort is not increased beyond this point. Unless the employer can freely adjust wages over time, they will need to make an educated guess as to what employees perceive as fair.

In the model, high unemployment benefits push fair wage perceptions upward; the impact of BI has not, to my knowledge, been studied or hypothesized. In general, the impact of BI is ambiguous. If employees take into consideration that a BI transfer is eventually paid for in taxes by those who are employed, the effect may be very similar. Employers may also anticipate that an employee who receives such a transfer might be less appreciative of wage increases, as they make less of a difference in total income: this can induce them to pay higher wages, if efficiency is still improved. This could boost gift exchange behavior. On the other hand, employers may feel that it is only fair to pay employees less when they already receive non-labor income. Lastly, it may be that an unconditional, universal transfer system would induce a widespread conviction that such generosity should be reciprocated by citizens (Van der Veen, 2019). Not engaging in paid work or other activities that benefit society would then leave people with a nagging sense of indebtedness that they resolve by engaging in paid work. Generous unemployment benefits or social security nets may have similar impact. 


\section{Experimental design}

Five experimental sessions were run at the Autonomous University of Barcelona in April 2018. A total of 80 university students were recruited from the LACESS laboratory's participant pool, and 76 showed up on time. Upon arrival, participants were assigned a seat in a computer lab $^{2}$ and tasked with playing a game with a fixed partner, one playing the part of employer, and one the employee. In the game, employers made wage offers, and employees decided whether they would work for the offered wage, and if so, how hard they would work. The only difference between sessions were the BI and conditional transfer (CT) treatments; the control session had no social security net. The aim was to generate information about the impact of BI on gift exchange behavior - that is, potential changes in wage offers, effort exerted, and the way wages and effort affect each other under different settings.

The design is based on the classic gift exchange experiment (Fehr et al., 1993). The most important modifications made for the study at hand are real effort, real leisure, and a repeated game format. This means that employees did not indicate hypothetical effort by choosing a number from 0 to 10 as in the original gift exchange experiment, but by completing small tasks (real effort). They were also allowed to use the internet when not working (real leisure), as opposed to being constrained to either working or doing nothing. Real effort and real leisure add more realistic elements to the game. Participants also knew beforehand that they would play with the same person in all rounds (repeated game format). This allows for an analysis of a continuous relationship where both parties may act in more pro-social ways to ensure better profits in the future. The exact research questions were as follows:

1. Does a simulated BI affect A. wages, B. offers, or C. the interaction of wages and offers in the gift exchange game?

2. Are these effects different from conditional transfers?

3. Does the size of the transfer make a difference?

\section{Design details}

Eight identical rounds were played in all sessions. At the beginning of each round, the employer could offer the employee a wage ranging from 0 to 120 experimental currency units (ECU). The employee could then decide whether to accept the offer. Those who accepted their offer had four minutes to solve up to 10 encryption tasks (coded and freely shared by Benndorf, Rau, \& Sölch, 2018). The encryption tasks were repetitive and required no previous knowledge. During the four-minute working period, employees (and employers) were free to surf the internet or otherwise relax, given that they did not disturb other participants. Participants were shown a $\log$ of past rounds before the next round began. After playing all rounds but before receiving their payment, subjects filled out an end survey. ${ }^{3}$ The English version of instructions given to participants are included as Appendix A.

For the control setting, payoff $(\pi)$ functions were

$$
\pi=v * 0.1 e-w
$$

for the employer, and

$$
\pi=w-c-(E-1)
$$

for the employee in each round. These functions applied when a labor contract was formed: an offer was made and accepted, and the minimum requirement of one correctly completed task was met by the employee. In the functions, $v$ is the maximum value (120 ECU) produced through labor; $e$ is the number of correctly completed tasks; $w$ is the wage (minimum 0, maximum $120 \mathrm{ECU}$ ); $c$ is the baseline cost of work (20 ECU); and $E$ is the total number of attempts to solve a task. Expressed verbally, both players' profits were impacted by the wage as well as the effort levels chosen, as is consistent with previous applications of the gift exchange experiment. Employers reap the value produced through labor and pay the promised wage. For employees, points were earned through wages. Each attempt to solve a task costs the employee one ECU except for the first attempt of each round, which is free of monetary cost. Baseline cost of work, set at $20 \mathrm{ECU}$, represents costs such as commuting or acquiring work-appropriate clothing. The payoff functions are adapted from Fehr et al. (1993). 
Whenever participants were faced with a decision, they were provided with a tailor-made calculator to see what outcomes would possible for each party.

In the BI treatments, all employees received 10 (BI10) or 20 (BI20) ECU per round in addition to whatever their earnings were otherwise. In the conditional transfer treatments employees also received 10 (CT10) or 20 (CT20) ECU, but only if they did not accept a wage offer, or an offer was not made in the first place. All five payoff functions for employees are presented in Table 1 below.

Table 1: Payoff functions for employees by treatment $(\pi=)$.

\begin{tabular}{lll}
\hline Setting & Offer made and accepted, $\mathbf{e}>\mathbf{0}$ & All other cases \\
\hline Control & $\mathrm{w}-\mathrm{c}-(\mathrm{E}-1)$ & 0 \\
BI10 & $\mathrm{w}-\mathrm{c}-(\mathrm{E}-1)+10$ & 10 \\
BI20 & $\mathrm{w}-\mathrm{c}-(\mathrm{E}-1)+20$ & 20 \\
CT10 & $\mathrm{w}-\mathrm{c}-(\mathrm{E}-1)$ & 10 \\
CT20 & $\mathrm{w}-\mathrm{c}-(\mathrm{E}-1)$ & 20 \\
\hline
\end{tabular}

\section{Hypotheses}

Note that in the BI treatment, extra points are added to employee's payoffs regardless of their choices. There is thus no specific incentive to behave differently under the treatment. It is possible that employees could interpret the BI transfer as a gift and, unable to reciprocate this gift to the experiment directly, increase their effort level instead. Those who are averse to inequality may also increase effort levels to share the benefit of the extra points. Similarly, employers may feel that it is only fair to pay employees less when they already receive extra points. Yet again, they may anticipate that an employee who receives extra points may need a higher wage offer to motivate them to work. Due to such opposing forces potentially influencing behavior, a null hypothesis is used here. $^{4}$

\section{Hypothesis 1. Neither BI treatment will result in changes in behavior.}

Unemployment benefits, on the other hand, act as an additional cost of working to employees: the benefit is lost when accepting a job. Thus, similar wage offers would be less enticing in the CT treatments compared to the control, and less effort would be exerted in return. Predicting this, employers might make higher offers than they would otherwise. As for interpreting wages as gifts, I anticipate there are two possible responses. Some participants may be inclined to see identical wages as equally generous regardless of the treatment, considering only the offer size itself. Others may appreciate an identical wage offer less in the CT treatment compared to the control, as the final profit for the employee is lower. If both types of participants are present in the sample, the average person would interpret a wage offer in the CT treatment as less valuable in terms of gifts than they would in the control setting. They would then reciprocate with a less valuable gift themselves, decreasing effort. As for the reactions of employers, the reverse is likely true. As the cost of accepting an offer is higher, a lower level of effort could be interpreted as a gift; or this cost could be disregarded, only taking mind of the benefits to the employer, which remain unchanged. The average person would then interpret the gift of effort as more valuable in the CT treatment, reciprocating with a higher offer than they would otherwise. Both effects would likely be stronger when the transfer is larger.

Hypothesis 2. Ceteris paribus, wage offers will be higher and effort will be lower in the CT treatments in comparison to the control setting.

Hypothesis 3. The effects will be stronger for the CT20 treatment than the CT10 treatment.

\section{Analysis and results}

\section{Description of the data}

The mean age of participants was 22.1 and the gender division roughly equal. One in four participants had attained a bachelor's degree. On average, political stance was slightly leaning to the left at 5.0 on a scale of 1 to 10. Average earnings in the experiment were 22.95 euros, including a 12 euro show-up fee, and sessions ran 
for approximately 90 to 120 minutes. Out of a theoretical maximum of 304 interactions (38 employer-employee pairs each playing eight rounds) a total of 279 observations were included in the final analysis. ${ }^{5}$ An interaction refers to choices made in one round: a wage offer made, and an effort level chosen in response. Due to the small sample sizes and potential selection bias, there were some differences between treatment groups, which were considered when running analyses. All data analysis was run using the R Statistics software.

\section{Gift exchange behavior in the experiment}

As has been established, gift exchange behavior is expressed through reciprocating high wages with high effort and vice versa. The gift exchange relationship must first be initiated by one party. To investigate whether such behavior occurred in the experiment, gift exchange behavior was first defined as a "yes or no" variable (dummy variable). A wage offer only counted as a gift when it was higher than the minimum required to enable positive payoffs for the employee ${ }^{6}$; effort levels were interpreted as gifts when they exceeded the minimum requirement of one correctly completed task.

Table 2 shows the proportion of wage offers and effort levels thus qualifying as gifts in each treatment. In total, around $70 \%$ of both offers made and effort exerted are interpreted as gifts. Approximately $60 \%$ of all interactions in the experiments were characterized by mutual gift exchange, where an offer higher than predicted was reciprocated with effort higher than 1 . The BI treatments have more wage offers qualifying as gifts than either the control or CT treatments. In both treatment types there are more instances of effort exceeding the minimum requirement than in the control setting. Mutual gift exchange was also more common in both treatments types when compared to the control. Here, the BI treatments show a much larger difference than the CT treatments.

Table 2: Proportion of interactions exhibiting gift exchange behavior by treatment.

\begin{tabular}{llll}
\hline & Offers above threshold & Effort above threshold & Mutual gift exchange \\
\hline Control & $66 \%$ & $54 \%$ & $44 \%$ \\
BI10 & $77 \%$ & $74 \%$ & $70 \%$ \\
BI20 & $88 \%$ & $77 \%$ & $75 \%$ \\
CT10 & $65 \%$ & $73 \%$ & $56 \%$ \\
CT20 & $66 \%$ & $71 \%$ & $59 \%$ \\
Total & $72 \%$ & $69 \%$ & $61 \%$ \\
\hline
\end{tabular}

Table 3 and Table 4 provide more information about wages and effort in each treatment, featuring the mean and median wage offers and effort levels as well as their correlation with each other. (The correlation coefficients are different because for offers, the effort level considered is from the previous round.) The control shows much lower levels of effort and offers than other settings, while differences between the four treatment groups are smaller. Highest offers are observed in the BI20 and CT20 treatments, and the lowest among treatment groups in CT10.

Table 3: Mean and median effort levels and correlation with offer by treatment.

\begin{tabular}{llll}
\hline Treatment & Mean & Median & Correlation with offer \\
\hline Control & 3,0 & 3,0 & 0,65 \\
BI10 & 4,7 & 5,0 & 0,78 \\
BI20 & 5,1 & 6,0 & 0,37 \\
CT10 & 4,5 & 5,0 & 0,55 \\
CT20 & 4,5 & 5,0 & 0,59 \\
Total & 4,4 & 5,0 & 0,61 \\
\hline
\end{tabular}

Table 4: Mean and median offers and correlation with lagged effort by treatment.

\begin{tabular}{llll}
\hline Treatment & Mean & Median & Correlation with effort \\
\hline Control & 38,5 & 42.0 & 0,38 \\
BI10 & 45,1 & 45,0 & 0,45
\end{tabular}




\begin{tabular}{llll} 
BI20 & 46,4 & 45,0 & 0,22 \\
CT10 & 40,6 & 42,0 & 0,41 \\
CT20 & 46,5 & 46,0 & 0,55 \\
Total & 43,4 & 45,0 & 0,43 \\
\hline
\end{tabular}

All in all, both treatment types are connected to more frequent expressions of gift exchange behavior, and larger transfers seem to elicit a larger difference. Interestingly, there is also a difference in correlations between wage offers and the following effort level. To be exact, the BI10 treatment shows a stronger correlation between offers and effort than average, and the reverse is true for the BI20 treatment. This is explored further in the next subsection.

\section{Regression analysis}

The tables in the last subsection communicate the results in a simple fashion. This subsection explores the relationship between treatments and behavior with a more fine-grained approach. First, two simple linear regressions with offers and effort as the respective dependent variables, and the treatments as independent variables, were run. The results are reported in the first columns of Table 5 and Table 6 . The results are not statistically significant other than for the CT treatments significantly increasing effort by approximately 1.5 more tasks completed per round. The effect on offers is not statistically significant for any treatment with this model, and the F-statistic is also not significant. ${ }^{7}$

Table 5: Regressions on effort levels with random effects and interaction terms.

\begin{tabular}{llll}
\hline Intercept & $3.02(0.42)^{* * *}$ & $3.09(0.29)^{* * *}$ & $0.184(0.36)$ \\
BI10 & $1.70(0.59)^{* *}$ & $1.56(0.39)^{* * *}$ & $0.114(0.50)$ \\
BI20 & $2.13(0.62)^{* * *}$ & $2.05(0.42)^{* * *}$ & $3.09(0.57)^{* * *}$ \\
CT10 & $1.48(0.64)^{*}$ & $1.25(0.43)^{* * *}$ & $0.785(0.61)$ \\
CT20 & $1.49(0.60)^{*}$ & $1.30(0.40)^{* *}$ & $0.354(0.55)$ \\
Offer & - & - & $0.068(0.01)^{* * *}$ \\
BI10*Offer & - & - & $0.024(0.02)^{* *}$ \\
BI20*Offer & - & - & $-0.028(0.01)^{* * *}$ \\
CT10*Offer & - & - & $0.009(0.01)$ \\
CT20*Offer & - & - & $0.004(0.01)$ \\
Random effects & No & Yes & Yes \\
Residual s.e. & 3.19 & 3.19 & 2.54 \\
Adjusted R2 & 0.037 & 0.036 & 0.390 \\
F-statistic & $3.50 * *$ & 3.44 & $19.48^{* * *}$ \\
DF & 260 & 260 & 255 \\
\hline
\end{tabular}

Table 6: Regressions on offer sizes with random effects and interaction terms.

\begin{tabular}{|c|c|c|c|}
\hline Intercept & $38.53(3.16)^{* * *}$ & $39.63(0.24)^{* * *}$ & $32.0(0.28)^{* * *}$ \\
\hline BI10 & $6.52(4.42)$ & $5.42(0.34)^{* * *}$ & $5.52(0.40)^{* * *}$ \\
\hline BI20 & $7.91(4.77)$ & $6.81(0.37)^{* * *}$ & $10.65(0.48)^{* * *}$ \\
\hline CT10 & $2.06(4.77)$ & $0.955(0.37)^{* * *}$ & $1.88(0.44)^{* * *}$ \\
\hline СТ20 & $7.96(4.57)$ & $6.85(0.35)^{* * *}$ & $6.74(0.41)^{* * *}$ \\
\hline Effort in $\mathrm{t}-1$ & - & - & $2.73(0.05)^{* * *}$ \\
\hline BI10*Effort & - & - & $-0.367(0.07)^{* * * *}$ \\
\hline BI20*Effort & - & - & $-1.89(0.08)^{* * * *}$ \\
\hline CT10*Effort & - & - & $-1.16(0.08)^{* * *}$ \\
\hline CT20*Effort & - & - & $-0.74(0.07)^{* * *}$ \\
\hline Random effects & No & Yes & Yes \\
\hline Residual s.e. & 24.71 & 24.72 & 21.51 \\
\hline Adjusted R2 & 0.003 & 0.003 & 0.175 \\
\hline F-statistic & 1.2 & 1.18 & $5.94^{* * *}$ \\
\hline DF & 272 & 272 & 232 \\
\hline
\end{tabular}

The analysis was then refined with a random effects model. ${ }^{8}$ This corrects for bias caused by the fact that one individual generates multiple observations (resulting in so-called autocorrelated error terms, which pose a problem 
for estimating regression coefficients). The new regression models are presented in the middle columns of Table 5 and Table 6 . It is immediately noticeable that all four treatments seem to have a statistically significant and positive effect of both offers and effort. The F-statistic for the model on offers is still not significant, meaning that the share of variation explained by the model is still very small. This changes when interaction effects are included in the model.

Interaction effects are the effects of two variables in conjunction. Here, they refer to the effect of the behavior of the other player in their previous turn and belonging to a certain treatment group. Such effects are of interest as they are at the heart of exploring differences in gift exchange behavior caused by treatments. In this model, the effect of wage offers in general is an increase of 0.068 more tasks completed per round, per a unit increase in the wage offer. The effect of belonging to the BI20 treatment group is an increase of 3.09 task completed per round. The interaction effect of belonging to the BI20 group and having received a particular wage offer is -0.028 ; this means that the effect of offers is weaker than in the other treatment groups, although still positive in total $(0.068-0.028=0.040)$. For BI10, the model suggests that reciprocal reactions to offers are stronger than in other treatments. In the CT treatments, there seems to be no difference compared to the control.

Noticeably, the treatment effects for BI10, CT10 and CT20 on effort are greatly reduced and lose significance after including offers and interaction effects in the model. This seems to be because the difference in effort is mostly connected to offer size instead of treatment. The BI20 treatment is an exception to this, exhibiting 3.09 more tasks completed per round compared to the control. The regression coefficients for treatment effects could also be biased towards zero due to overadjustment bias: this means that if the treatment caused a change in offer sizes, which in turn cause a change in effort, some of the effect of the treatment will be masked by controlling for offers. Due to the importance of interaction effects, this is an inevitable trade-off. Nevertheless, as the coefficients maintain a positive sign for all treatments, positive treatment effects could potentially be confirmed with a larger sample.

For wage offers, all coefficients in the third column are highly significant and carry the same interpretation: all treatment groups have a higher baseline for wage offers than the control group, but the impact of effort levels on following offers is weaker for all treatments. This difference is again most prominent in the BI20 treatment, where a unit increase in effort in the previous round increases offer size by only $2.73-1.89=0.84$ units. Nevertheless, the effect of effort on offers is present and positive in all treatments, meaning that high effort in the previous round still predicts higher offers in the current round. As for the baseline, offers in all treatments are higher than in the control, with the 20-unit transfers having a much larger increase: the BI20 treatment exhibits offers more than 10 units higher than in the control, compared to 5.52 for the BI10 treatment. For the CT treatments, these figures are 6.74 and 1.88 for CT20 and CT10 respectively.

\section{Discussion}

According to the analysis, gift exchange behavior was altered by the treatments applied. Baselines for offers and effort were higher in all four treatments. This would indicate a stronger tendency for gift exchange behavior. However, the heart of gift exchange theory is that higher wages and effort levels are part of a reciprocal relationship. It seems that for offers, the impact of past effort is in fact diminished by all four treatments. As for effort, the results vary: the BI10 treatment exhibits a stronger tendency to increase effort according to the wage offer, whereas the BI20 treatment shows a weaker tendency. Neither CT treatment seems to make a difference in this aspect.

One potential explanation for gift exchange behavior being so affected in the experiment is precisely the much higher baselines. That is, as neither effort or offers can increase indefinitely, most of the room for change could have been taken up by the initial increase. In line with this, the treatment where reciprocity in effort is strengthened compared to the control - BI10 - also shows a very small increase on the baseline. Another mechanism through which perceptions of wages may change with $\mathrm{BI}$ is anchoring. Anchoring refers to the effect on behavior from having seen a number related to the decision at hand. For example, if a salesman offers you a pair of shoes for $\$ 100$, and then another for $\$ 50$, the second pair seems cheaper than if you had first been shown a pair that costs $\$ 20$. People could be consciously or subconsciously comparing wage offers to their BI transfer. This could affect their perceptions of fair wages - for example, some may rule any wage under the BI transfer as too low to be fair. Both higher baselines and anchoring could occur in real life labor markets as well.

Another factor possibly influencing behavior is inequity aversion. A person averse to inequity dislikes an uneven share of points, either in all cases, when they themselves profit less than others, or only when others profit less. With the BI transfer, employees gain more from an interaction than in the control, other things held equal. Employers had no such benefit. In the CT treatments, employees who reject an offer gain larger payoffs than their partners, which participants may also find objectionable. However, if employers in the BI 
treatments wished to balance payoffs, they could have made lower offers; this did not happen. If employees chose to increase effort to 'even out the playing field', this would likely result in higher baseline effort and a weaker impact of offers on effort. This only happens in the BI20 treatment. All things considered, I do not believe inequity aversion has considerably polluted the results.

\section{Implications}

My results do not support the idea that BI would result in lower labor supply. In fact, there was a statistically insignificant difference between 'employment rates' in favor of the BI and CT treatments against the control. The results are also not in line with those of Haigner et al. (2012), where effort was not increased by a BI policy. This difference is potentially caused by the fact that in their design, wages could not vary. The boost in effort levels in the BI20 treatment especially also suggests that BI transfers could inspire employees to exert more effort in their jobs. This points to productivity being improved with the implementation of a BI policy.

The extra value created through work would not necessarily be reaped by society as a whole, but rather employers may benefit most from this effect. When productivity is increased, employers may hire fewer people to perform jobs, such as has happened with automation. If this leads to sharing work, or paid labor being performed by those with the least distaste for it, this can arguably be good for society (in a system where the unemployed are provided for). However, if labor supply is indeed not diminished at the same time, wages may be adjusted downward. This does not necessarily mean wages will plummet - even with relatively high involuntary unemployment, those lucky enough to have jobs are still often paid high wages. If the hypothesis of BI producing an upward pressure on wages from workers' improved bargaining power is correct, or if labor demand is increased through BI providing a boost to the economy, wage decreases could ultimately be cancelled out. My results show wage offers increasing in size with both BI and CT treatments, especially with higher-level transfers. This result should be put under pressure by introducing competition for jobs.

In the experiment, BI boosted offers and effort more than did CT's, but CT was also a significant change to the control which lacked social security nets. This accentuates the need to estimate the impact of implementing $\mathrm{BI}$ in comparison to the system currently in place. Ceteris paribus, societies with very generous social policy measures are less likely to see a big difference from BI. This is useful to keep in mind when assessing results from field experiments in different countries. Differences were also detected between cash transfers of different sizes, underlining the importance of careful experimental and policy design: size matters. A study conducted with a partial BI design may not yield much information about the impact of a full BI.

\section{Conclusion}

This paper has presented a laboratory experiment designed to investigate the impact of BI on wages and productivity. The design is based on the classic gift exchange experiment, featuring a repeated game format, a real-effort task with an option of real leisure, and two types of cash transfer treatments: conditional (CT) and unconditional (BI), simulated by extra points awarded to the employee. Both treatments were applied in two levels for transfers, 10ECU and 20ECU. All participants were subjected to only one treatment or the control setting. The subjects were 76 students of the Autonomous University of Barcelona who participated in one of five experimental sessions in April 2018, resulting in a total 279 observations of interactions over eight rounds.

The results indicate that a BI policy may have the capacity to inspire employees to exert more effort at their jobs, which improves productivity. This benefit can be reaped by employers, who can decrease demand for human labor or decrease wages. Other dynamic effects of BI on labor market behavior may cancel out the negative impact. The differing results between BI and CT treatments as well as between different sized transfers underline the need for careful experimental and policy design. In this experiment, wages were increased by both BI and CT treatments compared to the control. For effort, there is a robust result that effort was increased by the BI20 treatment, and more experiments with a larger sample size may confirm such an effect for the other treatments. These results should be put under stress by introducing more realistic circumstances to the design. For example, the addition of competition for jobs could shed light on who would reap the benefits of increased productivity.

As has been discussed in this paper, the impact of BI should be studied in terms of changes to the status quo, which does not often entail the complete lack of a social security net. Comparisons between BI and different policies such as Negative Income Tax, and regulations such as minimum wages would also be useful in terms of policy design where several options for policy reform are being considered. Lastly, it is possible that there are subject group differences in reactions to BI due to different values and life experiences on average in different societies. To confirm generalizability to different populations, similar experiments could be run in different 
countries and with participants including non-students. Further inspection into differences in behavior between groups such as men and women can also yield a more detailed picture of the impact of BI on labor market behavior when not only an average effect is of interest.

\section{Funding}

This work was supported by the National Plan for R + I (Government of Spain), (Grant Number: CSO201564740-R ("Behavioural Public Policies"). Finnish Cultural Foundation, Central Finland regional Fund, (Grant Number: Personal working grant).

\section{Appendix}

\section{A INSTRUCTIONS (FOR EMPLOYERS, CONTROL SESSION)}

\section{Welcome to the study!}

Please, put your phone on silent, and do not communicate with anyone in the room. If you need help, raise your hand, and we will assist you.

\section{Your role in the study.}

You have been randomly assigned the role of employee.

Another participant has been randomly assigned as your employer.

In the study, employers can make wage offers, and employees can work by solving tasks.

Your earnings in the study depend on your decisions and your employer's decisions.

Your employer remains the same for the duration of the study, but their identity will not be revealed to you at any point.

\section{Procedure.}

The study consists of several rounds.

Each round consists of three phases.

In the 1st phase, you can make a wage offer to your employee. (The wage offer must be a whole number between 0 and 120)

In the 2nd phase, your employee can accept or reject the offer.

In the 3rd phase, If the employee accepts the offer and can works by solving a task.

The third phase lasts four minutes. During this phase,

Employees can

- work by solving an encryption task 1-10 times,

- do whatever else they wish, like browsing the internet or checking their phone (without communicating with anyone in the room or making noise), or

- alternate between working and not working.

Employers can

- use the four minutes as they wish (without communicating with anyone in the room or making noise).

You can press the Windows-button to access the desktop at any time. Please, return to the study when the third stage ends. The monitors will notify you of the time.

\section{Accumulating points.}

Your earnings are represented by points.

Points depend on the wage offer and number of tasks solved.

The employer receives 12 points for each task the employee completes correctly, if the employee solves at least one task the offered wage to the employee. 
The employee receives the wage. The cost of working is 20 points for the employee. An attempt to solve a task, successful or failed, costs one additional point (the first attempt is free of cost).

If the employer makes no wage offer, the employee rejects the offer, or does not solve any tasks correctly, both gain zero points for the round.

\begin{tabular}{lll}
\hline & Cost & Benefit \\
\hline Employer & Wage & $12 \times$ solved tasks \\
Employee & $-20 \quad \begin{array}{l}-(\text { attempts to solve a } \\
\text { task }-1)\end{array}$ & Wage \\
\hline
\end{tabular}

For convenience, you are provided with a calculator in stages where you make decisions so that it may help you take decisions.

\section{Points and earnings.}

At the end of the game, your total points are converted to euros and you are paid in cash.

The conversion rate is $25 / 1$, meaning that 25 points are worth one euro.

Earnings are rounded to the nearest ten cents.

Both you and your employee start with 125 points.

If you ever go below 0 points, you are bankrupt and you and your employee will be excluded from the rest of the study. You will need to remain seated until the session is over. Your employee will be paid according to their total points so far.

At the end of the session, a $12 €$ participation fee will be added to your earnings.

Example 1. If you have 475 points at the end of the game, you will receive $375 / 25=15$ euros, plus the $12 €$ participation fee, totaling 28 euros.

Example 2. If you have 50 points at the end of the game, you will receive $50 / 25=2$ euros, plus the $12 €$ participation fee, totaling 14 euros.

Example 3. If you have less than 0 points at any point in the game, you will receive only the $12 €$ participation fee.

\section{Notes}

1 In the NIT studies run in the US, for example, it was found that female family members decreased their labor supply the most (Levine et al. 2005), suggesting that those with more unpaid responsibilities react more strongly to non-labor income.

2 The experiment was programmed and conducted with z-Tree (Fischbacher, 2007).

I 3 In addition to more standard socioeconomic information, such as age, gender, income and education level, some relevant questions from the World Values Survey (Inglehart et al. 2014) were replicated.

4 If an effect were observed, the larger BI transfer would likely yield stronger but otherwise similar results. Another possibility is there is a threshold value after which behavior is affected; in this case, the higher transfer could induce an effect, while the lower transfer would not.

5 One participant showed a severe lack of understanding of the rules, and their data was not used. Data after bankruptcies was also excluded from analysis. Participants who made extreme losses were declared bankrupt to avoid a situation where participants would need to pay back money the laboratory. They were not allowed to continue playing afterwards, and only received the show-up fee at the end of the session. Out of 76 participants, two ended up bankrupt.

6 More than 21 for settings 1-3, more than 31 for setting 4, and more than 51 for setting 5; these offers are just high enough that employees can make at least one point in the round.

7 The F-statistic is used to measure the statistical significance of a regression model. If the F-statistic is not statistically significant, it is plausible that the true regression coefficient for all variables included in the model is zero.

8 Wallace-Hussain estimators and the 'plm' package in R statistics were used for this step.

\section{References}

Akerlof, C. A. (1982). Labor contracts as partial gift exchange. The Quarterly Journal of Economics, 97(4), 543-569

Akerlof, G. A., \& Yellen, J. L. (1990). The fair wage-effort hypothesis and unemployment. The Quarterly Journal of Economics, 105(2), 255-283.

Beck, S., Pulkki-Brännström, A., \& San Sebastián, M. (2015). Basic income - healthy outcome? effects on health of an Indian basic income pilot project: A cluster randomised trial. Journal of Development Effectiveness, 7(1), 111-126. doi:10.1080/19439342.2014.974200

Benndorf, V., Rau, H. A., \& Sölch, C. (2018). Minimizing learning behavior in repeated real-effort tasks. Center for European, Governance and Economic Development Research Discussion Papers 343, University of Cöttingen, Department of Economics.

Birnbaum, S., \& Wispelaere, J. D. (2016). Basic income in the capitalist economy: The mirage of "Exit" from employment. Basic Income Studies, 11(1), 61-74. doi:10.1515/bis-2016-0013

Calnitsky, D. (2018). Debating basic income. Catalyst, 1(23), 63-90. 
Calnitsky, D. (2019). Basic income and the Pitfalls of randomization. Contexts, 18(1), 22-29.

Calnitsky, D., \& Latner, J. P. (2017). Basic income in a small town: Understanding the elusive effects on work. Social Problems, 64(3), 26-71.

Fehr, E., Kirchsteiger, G., \& Riedl, A. (1993). Does fairness prevent market clearing? An experimental investigation. The Quarterly Journal of Economics, 108(2), 437-459.

Fischbacher, U. (2007). Z-tree: Zurich toolbox for ready-made economic experiments. Experimental Economics, 10(2), 171-178.

Forget, E. L. (2011). The town with no poverty: The health effects of a Canadian guaranteed annual income field experiment. Canadian Public Policy, 37(3), 283-305.

Gilbert, R., Murphy, N. A., Stepka, A., Barrett, M., \& Worku, D. (2018). Would a basic income guarantee reduce the motivation to work? An analysis of labor responses in 16 trial programs. Basic Income Studies, 13(2). doi:10.1515/bis-2018-0011

Haigner, S., Höchtl, W., Jenewein, S., Schneider, F. G. \& Wakolbinger, F. (2012). Keep on working: Unconditional basic income in the lab. Basic Income Studies, 7(1), 1-19.

Inglehart, R., Haerpfer, C., Moreno, A., Welzel, C., Kizilova, K., Diez-Medrano, J., ... Puranen, B. (Eds.). (2014). World values survey: Round six country-pooled datafile version. Madrid: JD Systems Institute. http://www.worldvaluessurvey.org/WVSDocumentationWV6.jsp.

Kangas, O., Jauhiainen, S., Simanainen, M., \& Ylikännö, M. (2019). The basic income experiment 2017-2018 in Finland. Preliminary results. Reports and Memorandums of the Ministry of Social Affairs and Health 2019: 9.

Levine, R. A., Watts, H., Hollister, R., Williams, W., O'Connor, A., \& Widerquist, K. (2005). A retrospective on the negative income tax experiments: Looking back at the most innovative field studies in social policy. Published in Widerquist, Karl; Lewis, Michael Anthony; Pressman, Steven. (2005). The ethics and economics of the Basic Income Guarantee. Hamphshire: Alternative voices in contemporary economics, Ashgate

Mani, A., Mullainathan, S., Shafir, E., \& Zhao, J. (2013). Poverty impedes cognitive function. Science, 341(August), 976-980.

Marx, A., \& Peeters, H. (2008). An unconditional basic income and labor supply: Results from a pilot study of lottery winners. The Journal of Socio-Economics, 37(4), 1636-1659.

Noguera, J. A. \& De Wispelaere, J. (2006). A plea for the use of laboratory experiments in basic income research. Basic Income Studies, 1(2), 1-8.

Pech, W. J. (2010). Behavioral economics and the basic income guarantee. Basic Income Studies, 5(2), 1-17.

Van der Veen, R. (2019). Basic income experiments in the Netherlands? Basic Income Studies, forthcoming.

Widerquist, K. (2013). Independence, propertylessness and basic income. New York: Palgrave Macmillan.

Widerquist, K. (2018). The devil's in the caveats: A brief discussion of the difficulties of basic income experiments. CESifo Forum, 19(3), 30-35. 